\title{
A STUDY ON THE RETURN VOLATILITY OF THE COFFEE BEANS PRICE USING ARCH MODELS
}

\section{UM ESTUDO SOBRE A VOLATILIDADE DO RETORNO DO PREÇO DO CAFÉ USANDO MODELOS ARCH}

\author{
Sandra Cristina de Oliveira ${ }^{1}$ \\ ${ }^{1}$ Universidade Estadual Paulista \\ Faculdade de Ciências e Engenharia - Campus de Tupã \\ sandra.oliveira@unesp.br
}

\begin{abstract}
In the case of primary commodities, price volatility would arise mainly due to disturbances in supply, whereas for industrial raw materials, it would be the result of disturbances in demand. In the analysis of commodity markets can be seen that information, hedging, speculation and physical availability are factors that can influence their volatility. Moreover, increased volatility in commodity markets can justify the use of information-based processes for modeling the pattern of return volatility of these commodities. Since the relevance of autoregressive conditional heteroscedasticity $(\mathrm{ARCH})$ family models in the solution of problems in economic and financial areas due to their applicability and interpretation (the relation between return and volatility) have been provided, the aim of this work was to compare the Bayesian estimates for the parameters of ARCH processes with normal and Student's $t$ distributions for the conditional distribution of the return series of coffee beans price. In addition, informative prior distributions were suggested and posterior summaries were obtained by Monte Carlo Markov Chain simulation methods. Results show that the proposed Bayesian approach provides satisfactory estimates and that the ARCH process with Student's $t$ distribution adjusts better to the data.
\end{abstract}

Keywords: Bayesian approach; Informative prior distributions; MCMC methods.

RESUMO - Para commodities primárias, a volatilidade do preço pode surgir principalmente por causa de distúrbios na oferta, enquanto que, para matérias-primas industriais, pode ser resultado de distúrbios na demanda. Na análise de mercados de commodities primárias observa-se que informação, hedging, especulação e disponibilidade física são fatores que podem influenciar na volatilidade de tais commodities. Além disso, o aumento da volatilidade nos mercados dessas commodities pode justificar o uso de processos baseados em informação para a 
modelagem do padrão da volatilidade do retorno destas. Dada a relevância da família de modelos autoregressivos com heterocedasticidade condicional $(\mathrm{ARCH})$ na resolução de problemas das áreas de economia e finanças, devido à sua aplicabilidade e interpretação (relação entre retorno e volatilidade), o objetivo deste trabalho foi propor uma abordagem Bayesiana e comparar as estimativas dos parâmetros de processos ARCH com distribuições normal e $t$ de Student para a distribuição da série de retornos mensais do café. Foram sugeridas densidades a priori informativas e os sumários a posteriori foram obtidos por meio de métodos de simulação de Monte Carlo em Cadeias de Markov (MCMC). Os resultados mostram que a abordagem Bayesiana proposta proporciona estimativas satisfatórias e que o processo $\mathrm{ARCH}$ com distribuição $t$ de Student se ajusta melhor aos dados.

Palavras-chave: Abordagem Bayesiana; Distribuições a priori informativas; Métodos MCMC. 


\section{INTRODUÇÃO}

Heteroscedasticity is often studied as part of econometrics, particularly in economic and financial time series modeling and prediction, where the time-varying nature of the conditional variance is associated with the concept of volatility. An appropriate description of how the volatility changes over time is fundamental to evaluate the risk of the investments and the price of the options. Besides, a correct specification of the conditional variance is required for an efficient inference of the econometric timeseries model (ENDERS, 2009).

The analysis of volatility pattern of returns generated by commodities has important implications concerning the formulation of policies for the country's economic performance. The origin of volatility differs for different types of commodities. In the case of primary commodities, price volatility would arise mainly due to disturbances in supply, whereas for industrial raw materials, it would be the result of disturbances in demand. In the analysis of primary commodity markets can be seen that information, hedging, speculation and physical availability are key factors that can influence the volatility of those markets. Moreover, increased volatility in primary commodity markets can justify the use of information-based processes for modeling the pattern of return volatility of those commodities (SILVA; SÁFADI; CASTRO JUNIOR, 2005).

A large variety of models exists to estimate the volatility of return series. The most common in the literature are the autoregressive conditional heteroscedasticity (ARCH) models, suggested by Engle (1982), and its extension, the generalized $\mathrm{ARCH}$ (GARCH) models, proposed by Bollerslev (1986). The models characterize a non-linear dependence among returns due to the serial dependency of conditional variance. Bollerslev (2008) provided an extensive review of the models' characteristics.
There are many works in the literature about the ARCH family models under a Bayesian approach. Geweke (1989) presented one of the first investigations for $\mathrm{ARCH}$ family models in which a special reparameterization case employed noninformative prior distributions. Estimates of parameters were obtained from Monte Carlo simulation algorithms. Nakatsuma (2000) used normal prior distributions for the parameters of ARMA-GARCH models and the Metropolis-Hastings algorithm to determine posterior summaries. Ausín and Galeano (2007) suggested a Bayesian approach for GARCH models with errors generated by Gaussian mixtures. Barreto, Andrade and Oliveira (2008) compared Bayesian and maximum likelihood methods by simulated series, following ARCH processes, with different orders and under conditions of finite and infinite variance. Moreover, Andrade and Oliveira (2011) presented a Bayesian approach for ARCH models with normal prior distributions for their respective parameters and compared credibility intervals with bootstrap intervals by employing index return series of the Brazilian financial market. Finally, Oliveira and Andrade (2012) compared the complete Bayesian method and the empirical Bayesian method for ARCH models using Brazilian financial time series and, Oliveira and Andrade (2013) constructed different Bayesian approaches for the parameters of processes of ARCH family with normal and Student's $t$ conditional distributions of the return series using a non-informative prior distribution.

Since the context and the relevance of the ARCH family models in the solution of problems in the economic and financial areas due to their applicability and interpretation (the relation between return and volatility) have been provided, current investigation compares the Bayesian estimates obtained for the parameters of $\mathrm{ARCH}$ processes with normal and Student's $t$ distributions for the conditional distribution of the return series of 
coffee beans price. Informative prior distributions were suggested and a reparameterization of the models studied was taken into account for each case to map the parameter's space on real space. The procedure adopts normal prior distributions for the transformed parameters. Posterior summaries were obtained by Monte Carlo Markov Chain (MCMC) simulation methods.

\section{PROCEDURES}

The regression model proposed by Engle (1982) with its mean zero and expressed as a linear combination of exogenous variables, exhibits the following structure:

$$
\begin{aligned}
& z_{t} \mid \Omega_{t-1} \sim P\left(0, h_{t}\right) \\
& h_{t}=\alpha_{0}+\sum_{j=1}^{q} \alpha_{j} z_{t-j}^{2}
\end{aligned}
$$

where $z_{t}$ represents return series; $P()$ is the parametric distribution, usually normal or Student's $t$; and, $\Omega_{t-1}$ is the set of information available up to time $t-1$.

The interpretation for the model defined in (1)-(2) is that returns in linear regression follow an autoregressive conditional heteroscedasticity of the order $q$.

So that model (1)-(2) is plausible ( $h_{t}>0$ during $t$ ), there must be $\alpha_{0}>0$ and $\alpha_{j} \geq 0$ for $j=1, \ldots, q$. In addition, process $z_{t}$ has finite variance and therefore stationary covariance if, and only if, all the roots of the polynomial

$$
1-\sum_{j=1}^{q} \alpha_{j} l^{j}
$$

lie outside the unit radius circle. It may be thus shown that the unconditional variance of $z_{t}$ is given by

$$
\alpha_{0} /\left(1-\sum_{j=1}^{q} \alpha_{j}\right)
$$

whose condition for stationary covariance process is $\sum_{j=1}^{q} \alpha_{j}<1$.

Let $Z=\left\{z_{t}, t=1,2, \ldots, T\right\}$ be a trajectory of the return process $z_{t}$. If normality holds for $\varepsilon_{t}$, the likelihood function of $z_{t}$, $t=q+1, \ldots, T, \quad$ conditioned to $q$ first observations (presumed to be known) is given by

$$
L_{1}(Z \mid \alpha)=(2 \pi)^{-\frac{(T-q)}{2}} \prod_{t=q+1}^{T}\left(\frac{1}{h_{t}}\right)^{1 / 2} \exp \left\{-\frac{z_{t}^{2}}{2 h_{t}}\right\}
$$

with $\alpha=\left(\alpha_{0}, \alpha_{1}, \ldots, \alpha_{q}\right)^{\prime}$.

Presuming that $\varepsilon_{t}$ has a standard Student's $t$ distribution, or rather, $\varepsilon_{t}=\frac{t_{v}}{\sqrt{v /(v-2)}}$ such that $t_{v} \sim$ Student's $t$ with $v$ degrees of freedom, the likelihood function of $z_{t}, t=q+1, \ldots, T$, conditioned to $q$ first observations, is given by Morettin (2008):

$$
L_{2}(Z \mid \alpha)=\prod_{t=q+1}^{T} \frac{\Gamma((v+1) / 2)}{\Gamma(v / 2) \sqrt{(v-2) \pi}}\left(\frac{1}{h_{t}}\right)^{1 / 2}\left(1+\frac{z_{t}^{2}}{h_{t}(v-2)}\right)^{\frac{-(v+1)}{2}}
$$

with $\alpha=\left(\alpha_{0}, \alpha_{1}, \ldots, \alpha_{q}\right)^{\prime}$ and for some $v$.

The likelihood functions described in (5) and (6) may be maximized with regard to the respective unknown parameters $\alpha$.

In Bayesian context, the employment of the conditioned likelihood function instead of the exact likelihood function may be undertaken without any great precision loss in the estimates. This is due to the fact that one of the main advantages of Bayesian inference lies in the possibility of adjusting models, even in small samples.

Then, let $Z=\left\{z_{t}, t=1,2, \ldots, T\right\}$ be an observed trajectory of the return. The Bayesian approach for the inference of parameters of $\mathrm{ARCH}(q)$ processes starts from the joint likelihood function $L(Z \mid \alpha)$ defined by this trajectory with the prior density $\pi(\alpha)$ (it reflects previous knowledge on the distribution of the parameters) by Bayes rule $\pi(\alpha \mid Z) \propto L(Z \mid \alpha) \pi(\alpha)$

The expression $\pi(\alpha \mid Z)$ is called posterior density of parameter(s) of interest and explains how these randomized variables are distributed after data have been 
complied with.

The necessary condition for the stationary covariance allows to insure variation ranges for the parameters $\alpha_{i}, i=0,1, \ldots, q$. This way, it can be guaranteed that there are intervals $\left[a_{i}, b_{i}\right]$, $i=1,2, \ldots, q$ with $a_{i}>0$ and $b_{i}<1$, such that $a_{i} \leq \alpha_{i} \leq b_{i}$. It can be also considered $a_{0} \leq \alpha_{0} \leq b_{0}$, with $a_{0}>0$ and $b_{0} \leq E\left(z_{t}^{2}\right)$ (ANDRADE; OLIVEIRA, 2011).

Since this approach makes intensive use of MCMC algorithms, it is more advantageous to choose a parameter transformation that maps the intervals $\left(a_{i}, b_{i}\right)$ into the domain $(-\infty,+\infty)$. For this purpose, it was reparameterized the components of the parameter vector $\alpha$ (OLIVEIRA; ANDRADE, 2012), obtaining a new vector $\varphi=\left(\varphi_{0}, \varphi_{1}, \ldots, \varphi_{q}\right)^{\prime}$, whose components are given by

$\varphi_{i}=\log \left(\frac{\alpha_{i}-a_{i}}{b_{i}-\alpha_{i}}\right), i=0,1,2, \ldots, q$

During the implementation of the MCMC techniques this reparameterization allows the generation of values for $\alpha_{i}$ that are more often closer to the mean of the interval, i.e. $\left(a_{i}+b_{i}\right) / 2$, than to the limits of the interval. Values for $a_{i}$ and $b_{i}$ may be chosen based on some prior information, for instance, previous studies on the series under analysis.

Due to (8), the likelihood functions in (5) and (6) can now be expressed as

$$
L_{1}(Z \mid \alpha)=(2 \pi)^{-(T-q) / 2} \prod_{t=q+1}^{T}\left(\frac{1}{h_{t}}\right)^{1 / 2} \exp \left\{-\frac{z_{t}^{2}}{2 h_{t}}\right\}
$$

and

$L_{2}(Z \mid \alpha)=\prod_{t=q+1}^{T} \frac{\Gamma((v+1) / 2)}{\Gamma(v / 2) \sqrt{(v-2) \pi}}\left(\frac{1}{h_{t}}\right)^{1 / 2}\left(1+\frac{z_{t}^{2}}{h_{t}(v-2)}\right)^{-(v+1) / 2}$

where the parameters $\alpha_{i}$ of the original volatility function $h_{t}(\varphi)$ are adequately transformed into $\varphi_{i}$.
Assuming that $\varphi_{i}$ 's are independent, with normal prior distributions $\pi\left(\varphi_{i}\right) \sim \operatorname{Normal}\left(0, \sigma_{i}^{2}\right), \quad i=0,1,2, \ldots, q$ the joint prior distribution for $\varphi=\left(\varphi_{0}, \varphi_{1}, \ldots, \varphi_{q}\right)^{\prime}$ is given by

$$
\pi(\varphi) \propto \prod_{i=0}^{q}\left(\frac{1}{\sigma_{j}}\right)^{1 / 2} \exp \left\{-\frac{\varphi_{i}^{2}}{2 \sigma_{i}^{2}}\right\}
$$

Using (9), (10) and (11), the joint posterior distributions of $\varphi$ are expressed as

$$
\begin{aligned}
\pi_{1}(\varphi \mid Z) & \propto \prod_{t=q+1}^{T}\left(\frac{1}{h_{t}(\varphi)}\right)^{1 / 2} \exp \left\{-\frac{z_{t}^{2}}{2 h_{t}(\varphi)}\right\} \\
& \times \prod_{i=0}^{q}\left(\frac{1}{\sigma_{i}}\right)^{1 / 2} \exp \left\{-\frac{\varphi_{i}^{2}}{2 \sigma_{i}^{2}}\right\}
\end{aligned}
$$

$$
\begin{aligned}
\pi_{2}(\varphi \mid Z) & \propto \prod_{t=q+1}^{T}\left(\frac{1}{h_{t}(\varphi)}\right)^{1 / 2}\left(1+\frac{z_{t}^{2}}{h_{t}(\varphi)(v-2)}\right)^{-(v+1) / 2} \\
& \times \prod_{i=0}^{q}\left(\frac{1}{\sigma_{i}}\right)^{1 / 2} \exp \left\{-\frac{\varphi_{i}^{2}}{2 \sigma_{i}^{2}}\right\}
\end{aligned}
$$

Thus, the conditional posterior distributions of $\varphi_{i}, i=0,1, \ldots, q$ are given by

$$
\begin{aligned}
& \pi_{1}\left(\varphi_{i} \mid \varphi_{-i}, Z\right) \propto L_{1}(Z \mid \varphi) \pi\left(\varphi_{i}\right) \\
& (14) \pi_{2}\left(\varphi_{i} \mid \varphi_{-i}, Z\right) \propto L_{2}(Z \mid \varphi) \pi\left(\varphi_{i}\right)
\end{aligned}
$$

where $\varphi_{-i}$ is a vector with the model parameters except for the parameter $\varphi_{i}$.

Posterior densities have forms that are only similar to those of density functions of known probability. Consequently, the analytic calculation of the parameters' quantities of interest, such as means, mode, medians, standard deviation and others becomes impossible. The issue may be solved by Monte Carlo Markov Chain (MCMC) simulation methods.

The MCMC algorithm to be described next comprises the combined use of the Gibbs sampler (CASELLA; GEORGE, 1992) and Metropolis-Hastings (MH) (CHIB; GREENBERG, 1995) algorithms. The conditional posterior densities shown in (14) and (15) are used by the MCMC algorithm to generate a sample from the posterior 
densities given by (12) and (13), respectively. The use of the $\mathrm{MH}$ algorithm within the Gibbs sampler is required since the conditional posterior densities do not have closed forms.

Then, assuming a quadratic loss function, the Bayesian estimates for the parameters are obtained by means of the expected value of the sample generated from the posterior density.

MCMC Algorithm: Gibbs sampler with Metropolis-Hastings

Step 1: Provide the arbitrary initial values for $\varphi^{(0)}=\left(\varphi_{i}^{(0)}\right), i=0,1, \ldots, q \quad$ and compute $\alpha^{(0)}=\left(\alpha_{i}^{(0)}\right), i=0,1, \ldots, q$. Execute $k=1$.

Step 2: Generate a new value $\gamma$ from the conditional density $\pi\left(\varphi_{i} \mid \varphi_{-i}, Z\right)$ where

$\varphi_{-j}=\left[\varphi_{0}^{(k-1)}, \varphi_{1}^{(k-1)}, \ldots, \varphi_{i-1}^{(k-1)}, \varphi_{i+1}^{(k-1)}, \ldots, \varphi_{q}^{(k-1)}\right]$

and

$\varphi^{(k)}=\left[\varphi_{0}^{(k-1)}, \varphi_{1}^{(k-1)}, \ldots, \varphi_{i-1}^{(k-1)}, \gamma, \varphi_{i+1}^{(k-1)}, \ldots, \varphi_{q}^{(k-1)}\right]$.

Step 3: Calculate the probability of accepting the new value $\gamma$ in the $\varphi_{i}^{(k-1)}$ place

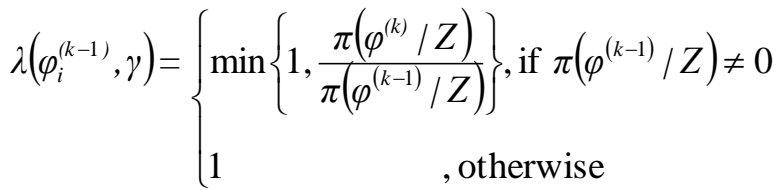

Step 4: Generate a uniform random variable $u \sim U(0,1)$ and execute

$\varphi_{i}^{(k)}=\left\{\begin{array}{cl}\gamma & , \text { if } u \leq \lambda\left(\varphi_{i}^{(k-1)}, \gamma\right) \\ \varphi_{i}^{(k-1)} & , \text { otherwise }\end{array}\right.$.

Step 5: Repeat Step 2 to Step 4 for $i=0,1, \ldots, q$

Step 6: Execute $k=k+1$ and return to Step 2 until the convergence is verified with some criterion (in this study will be used the Geweke criterion (GEWEKE, 1992)).

After the MCMC convergence, the original parameters $\alpha_{i}, i=0,1, \ldots, q$, may be recuperated by means of the inverse transformation

$\alpha_{i}=\frac{b_{i} e^{\varphi_{i}}+a_{i}}{1+e^{\varphi_{i}}}, i=0,1,2, \ldots, q$

The prediction of the conditional variance of an $\mathrm{ARCH}(q)$ model, $j$ steps ahead with origin in $t$, is given by $\hat{h}_{t}(j)=\alpha_{0}+\sum_{i=1}^{q} \alpha_{i} \hat{h}_{t}(j-i)$

where $\hat{h}_{t}(j-i)=z_{t-i+j}^{2}$, if $j-i \leq 0$.

In the Bayesian approach, the expected value with respect to the posteriori density of the parameters $\alpha$ can be approximated by the Monte Carlo estimate considering the sample $\alpha^{(k)}, k=1,2, \ldots, M$ generated by the MCMC algorithm. Thus, we have

$\widehat{h}_{t}(j)=\frac{1}{M} \sum_{k=1}^{M}\left(\alpha_{0}{ }^{(k)}+\sum_{i=1}^{q} \alpha_{i}{ }^{(k)} \widehat{h}_{t}(j-i)\right)$

\section{EMPIRICAL APPLICATIONS}

The data refer to historical series of monthly spot price in dollars (price/ $\mathrm{kg}$ ) of coffee beans paid to the Brazilian producer. The series covers the period January 1967 to April 2008, with a total of 496 observations (www.ipeadata.gov.br). Let $p_{t}$ be the monthly mean of the coffee price and then returns are given by $y_{t}=\ln \left(p_{t} / p_{t-1}\right)$. For investors (producers), returns of an asset are complete and independent summaries of the scale of investment opportunity. In addition, returns are easier to manipulating than prices because of statistical properties more tractable. Some descriptive statistics for the returns of coffee prices are reported in Table 1.

Table 1. Descriptive statistics for the return of the coffee series.

\begin{tabular}{c|c}
\hline monthly mean return & 0.005997 \\
\hline asymmetry coefficient & 0.421951 \\
\hline kurtosis coefficient & 4.704808 \\
\hline standard deviation non conditional & 0.091165 \\
\hline
\end{tabular}

Figure 1(a) illustrates coffee prices and their respective returns and Figure $1(b)$ shows the behavior of the squared returns. The sample kurtosis coefficient shows that the return series is leptokurtic, relative to the normal distribution, which, along with a visual inspection in Figure $1(a)$, shows that 
the return series has signs of heteroscedasticity and volatility clustering, features shared with the economic and financial time series. The estimated autocorrelations for the squared returns in Figure 1(b) also show signs of predictability, an evidence of $\mathrm{ARCH}$ effects.

Figure 1. Price and return of the coffee series (a) and autocorrelation functions of the squared return (b).

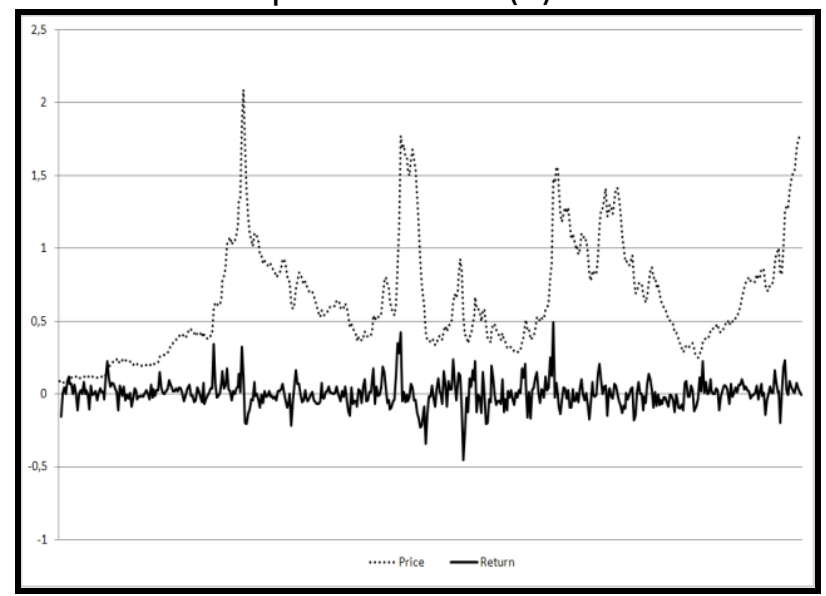

(a)

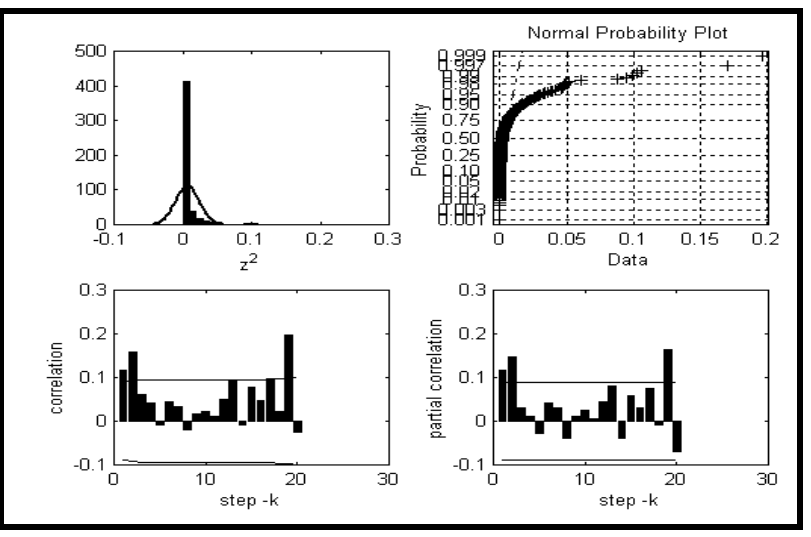

(b)

First, we fit $\operatorname{ARCH}(q)$ models with different orders to returns of the coffee time series. The orders of the $\mathrm{ARCH}(q)$ models (with normal and $t$ distributions for $\varepsilon_{t}$ ) were selected by the predictive ordinate criterion (POC) (CARLIN; CHIB, 1995).

$\mathrm{POC}$ is a Bayesian criterion based on the concept of predictive density in its definition, therefore, it compares what is predicted to what is observed for making the choice between models (VEIGA; VIVANCO, 2012). This criterion selects the most qualified and parsimonious model which, in turn, is also the model that presents more robust predictions.

All the computer routines were implemented using the MATLAB ${ }^{\circledR}$ software.

Both situations a chain of 50,000 iterations was simulated within the implementation of the Gibbs sampler with Metropolis-Hastings algorithm. Moreover, $50 \%$ of values were discarded to decrease the effect of initial conditions. Values spaced in fives, totaling a sample of $M=5,000$ observations, were established. The convergence of parameters was verified by Geweke criterion (G.C.), at 5\% significance, under the null hypothesis $\mathrm{H}_{0}$, which was established for values obtained between 1.96 and 1.96 (GEWEKE, 1992).

Values for $a_{i}$ and $b_{i}$ must be chosen based on some prior information. In this paper, $a_{i}$ and $b_{i}$ were chosen based on studies in Silva, Sáfadi and Castro Junior (2005) about the price and return of the coffee series covering the period January 1967 to April 2002.

In this study, the adjusted models to the returns of the coffee series, according to $\mathrm{POC}$, were: $\mathrm{ARCH}(2)$ model with $\mathrm{POC}=$ $4.238966 \mathrm{e}+013$ with normal distribution for $\varepsilon_{t}$ (M1) and $\mathrm{ARCH}(2)$ model with $\mathrm{POC}=$ $4.259268 \mathrm{e}+013$ with $t$ distribution for $\varepsilon_{t}$ (M2).

Table 2 shows Bayesian estimates and 95\% credibility intervals (C.I.) for those models, and Figure 2 illustrates the estimated volatility from estimates obtained within the Bayesian approach by the best adjustment model, or rather, $\mathrm{ARCH}(2)$ model with $t$ distribution for $\varepsilon_{t}$ (because this model presented the greatest value of $\mathrm{POC}$ ). 
Table 2. Bayesian estimates of the $\mathrm{M} 1$ and M2 models.

\begin{tabular}{c|c|c|c}
\hline M1 & Mean & C.I. (95\%) & G.C. \\
\hline$\alpha_{0}$ & 0.004167 & $0.004126 ; 0.004207$ & -0.860718 \\
\hline$\alpha_{1}$ & 0.200220 & $0.195759 ; 0.204521$ & -0.230901 \\
\hline$\alpha_{2}$ & 0.150125 & $0.146811 ; 0.153428$ & 0.206746 \\
\hline $\mathrm{M} 2$ & Mean & C.I. $(95 \%)$ & G.C. \\
\hline$\alpha_{0}$ & 0.004165 & $0.004161 ; 0.004169$ & 0.145433 \\
\hline$\alpha_{1}$ & 0.197857 & $0.193561 ; 0.202205$ & 1.624371 \\
\hline$\alpha_{2}$ & 0.148829 & $0.145465 ; 0.152081$ & 1.453448 \\
\hline
\end{tabular}

Figure 2. Estimated volatility for return of the coffee series using ARCH(2) model with $t$ distribution.

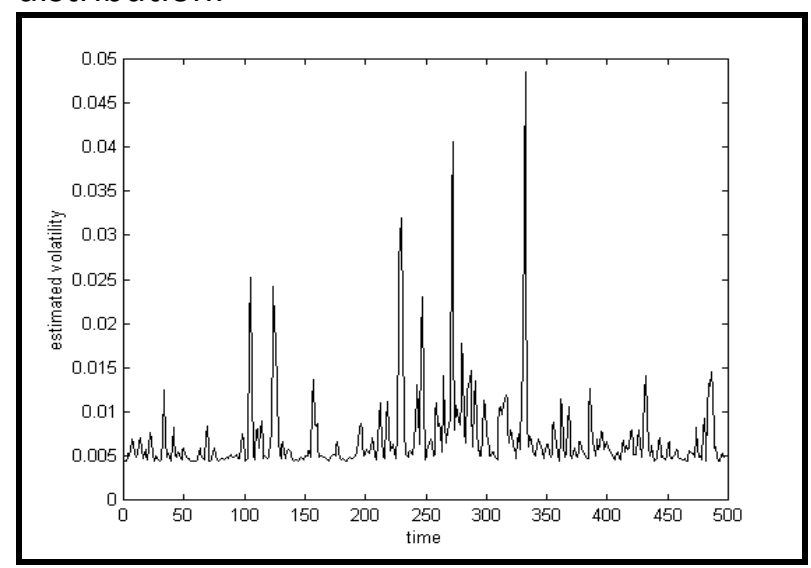

Figure 3 shows the forecast one step ahead for the return volatility of the coffee series over a period of 12 months.

Figure 3. Forecast of volatility of the return using $\mathrm{ARCH}(2)$ model with $t$ distribution over a period of 12 months (May 2008 to April 2009).

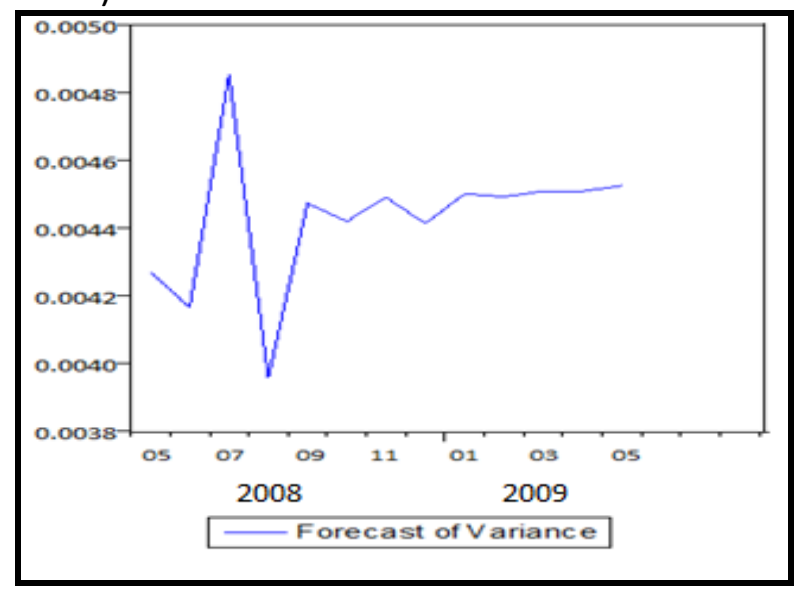

\section{FINAL CONSIDERATIONS}

In general, it is important to emphasize the feasibility of the Bayesian approach in the inference of the parameters of ARCH family processes, since it allows the possibility of incorporating the experience of experts in finance and economy, which is a highly relevant issue within the analysis of economic and financial series.

In this paper, we performed an empirical Bayesian analysis, through a detailed study. However, due to the complexity of this analysis, posterior estimates could only be found numerically and, so we used MCMC simulation algorithms.

The results show that, as a rule, the Bayesian approach provides satisfactory estimates and is entirely viable in volatility return modeling. Besides, the proposal of informative prior distributions, coupled to a reparameterization of the models under analysis, provided a faster convergence of the inference process of parameters of $A R C H$ family models by MCMC methods.

In terms of implications for policy formulation, the results empirical suggest that the creation and promotion of the use of instruments market-based hedging strategies may be appropriate face of high volatility and persistence of strong shocks checked to the volatility of these commodity returns.

\section{REFERENCES}

ANDRADE, M. G.; OLIVEIRA, S. C. A comparative study of Bayesian and Maximum Likelihood approaches for ARCH models with evidence from Brazilian financial series. New Mathematics and Natural Computation, v.7, n.2, p. 347-361, 2011. https://doi.org/10.1142/S179300571100197 $\underline{4}$

AUSíN, M. C.; GALEANO, P. Bayesian Estimation of the Gaussian Mixture GARCH Model. Computational Statistics and Data Analysis, v.51, n.5, p.2636-2652, 2007. 
BARRETO, G. A.; OLIVEIRA, S. C.; ANDRADE, M.G. Estimação de Parâmetros de Modelos $\mathrm{ARCH}(\mathrm{p})$ : Abordagem Bayes-MCMC versus Máxima Verossimilhança. Revista Brasileira de Estatística, v.69, n.1, p.7-24, 2008.

BOLLERSLEV, T. Generalized Autoregressive Conditional Heteroscedasticity. Journal of Econometrics, v.31, n.3, p.307-327, 1986. https://doi.org/10.1016/03044076(86)90063-1

BOLLERSLEV, T. Glossary to ARCH (GARCH). Research paper, School of Economics and Manangement, University of Aarthus (2008). Electronic copy available at: http://ssrn.com/abstract=1263250. https://doi.org/10.2139/ssrn.1263250

CARLIN, B.; CHIB, S. Bayesian Model Choice via Markov Chain Monte Carlo Methods. Journal of the Royal Statistical Society, v.57, n.3, p.473-484, 1995. https://doi.org/10.1111/i.25176161.1995.tb02042.x

CASELLA, G. E.; GEORGE, E. I. Explaining the Gibbs sampler. The American Statistician, v.46, n.8, p.167-174, 1992. https://doi.org/10.1080/00031305.1992.104 $\underline{75878}$

CHIB, S.; GREENBERG, E. Understanding the Metropolis-Hastings Algorithm. The American Statistician, v.49, n.4, p.327-335, 1995.

https://doi.org/10.1080/00031305.1995.104 $\underline{76177}$

ENDERS, W. Applied Econometric Times Series. New Jersey: Wiley, 2009. 544p.

ENGLE, R. Autoregressive Conditional Heteroscedasticity with Estimates of the Variance of UK Inflation. Econometrica, v.50, n.4, p.987-1007, 1982. https://doi.org/10.2307/1912773
GEWEKE, J. Exact Predictive Densities for Linear Models with ARCH Disturbances. Journal of Econometrics, v.40, n.1, p. 63-86, $1989 . \quad$ https://doi.org/10.1016/03044076(89)90030-4

GEWEKE, J. Evaluating the Accuracy of sampling-based approaches to calculating posterior moments (with discussion). Bayesian Statistics, v.4, p.164-193, 1992.

MORETTIN, P. A. Econometria Financeira. São Paulo: Edgard Blucher Ltd., 2008. 400p.

NAKATSUMA, T. Bayesian Analysis of ARMAGARCH Models: A Markov Chain Sampling Approach. Journal of Econometrics, v.95, n.1, p.57-69, 2000.

https://doi.org/10.1016/S03044076(99)00029-9

OLIVEIRA, S. C.; ANDRADE, M. G. Comparison between the complete Bayesian method and empirical Bayesian method for ARCH models using Brazilian financial time series. Pesquisa Operacional, v.32, n.2, p.293-313, 2012. https://doi.org/10.1590/S0101$\underline{74382012005000019}$

OLIVEIRA, S. C.; ANDRADE, M. G. Stochastic models with heteroskedasticity: A Bayesian approach for Ibovespa returns. Acta Scientiarum. Technology, v.35, n.2, p.339347, 2013. https://doi.org/10.4025/actascitechnol.v35i2 .13547

SILVA, W.; SÁFADI, T.; CASTRO JUNIOR, L. Uma análise empírica da volatilidade do retorno de commodities agrícolas usando modelos ARCH: os casos do café e da soja. Revista de Economia e Sociologia Rural, v.43, n.1, p.35-42, 2005. https://doi.org/10.1590/S0103$\underline{20032005000100007}$

VEIGA, E. P.; VIVANCO, M. J. F. A medida L como critério de comparação de modelos: 
Uma revisão da literatura. Revista Brasileira

de Biometria, São Paulo, v.30, n.3, p.343-

352, 2012. 